\title{
Association between ratio of measured extracellular volume to expected body fluid volume and renal outcomes in patients with chronic kidney disease: a retrospective single-center cohort study
}

\author{
Reibin Tai ${ }^{1}$, Yasushi Ohashi ${ }^{*}$, Sonoo Mizuiri ${ }^{1,2}$, Atsushi Aikawa ${ }^{1}$ and Ken Sakai ${ }^{1}$
}

\begin{abstract}
Background: Excess extracellular volume is a major clinical problem in patients with chronic kidney disease (CKD). However, whether the extracellular volume status is associated with disease progression is unclear. We investigated the association between the extracellular volume status and renal outcomes.

Methods: We performed a retrospective cohort study of 149 patients with CKD who underwent bioelectrical impedance analysis (BIA) from 2005 to 2009. Patients were categorized according to tertiles of extracellular volume status. The extracellular volume status was assessed by examining the ratio of extracellular water measured by BIA $\left(E C W_{B I A}\right)$ to the total body water calculated using the Watson formula (TBW Watson). The main outcomes were adverse renal outcomes as defined by a decline of $\geq 50 \%$ from the baseline glomerular filtration rate or initiation of renal replacement therapy.

Results: A higher \%ECW BIA $/ T B W_{\text {Watson }}$ ratio tended to be associated with older age, male sex, diabetes mellitus, resistant hypertension, lower renal function, lower serum albumin levels, higher proteinuria levels, and a higher frequency of furosemide use. In the multivariate analysis, proteinuria remained independently associated with the \% $\mathrm{ECW}_{\mathrm{BIA}} / \mathrm{TBW} \mathrm{W}_{\text {Watson }}$ ratio. Both the intracellular and extracellular water volumes decreased with age (correlation between ICW and age, $r=-0.30, P<0.001$; correlation between ECW and age, $r=-0.17, P=0.03)$. Consequently, the $\% E_{C W}$ BIA in the body fluid composition increased with age. During a median follow-up of 4.9 years, patients in the highest tertile of the \%ECW $\mathrm{BIA}_{\mathrm{A}} / \mathrm{TBW}$ Watson ratio were at greater risk of adverse renal outcomes (16.6 per 100.0 patient years) than were those in the lowest tertile (8.1 per 100.0 patient years) or second tertile (5.6 per 100.0 patient years) (log-rank $P=0.005)$. After adjustment for covariates, the \% $\mathrm{ECW}_{\mathrm{BIA}} / \mathrm{TBW}$ Watson $_{\text {ratio was significantly }}$ associated with adverse renal outcomes (hazard ratio, 1.21; $95 \%$ confidence interval, 1.10-1.34; $P<0.001$ ).

Conclusions: The ECW BIA $/ T B W_{\text {Watson }}$ ratio was independently associated with adverse renal outcomes. Proteinuria was independently associated with the extracellular volume status. The balance between ICW and ECW changes with age in that the percentage of ECW content in the body fluid composition increases. Elderly patients with CKD may thus be susceptible to volume overload.
\end{abstract}

Keywords: Chronic kidney disease, Extracellular volume excess, Kidney disease progression

\footnotetext{
*Correspondence: ohashiy@med.toho-u.ac.jp

'Department of Nephrology, School of Medicine, Faculty of Medicine, Toho

University, 6-11-1 Omori-Nishi, Ota-ku, Tokyo 143-8541, Japan

Full list of author information is available at the end of the article
} 


\section{Background}

Excess extracellular volume is a major clinical problem in patients with chronic kidney disease (CKD) and causes lower extremity edema, hypertension, pulmonary vascular congestion or edema, and heart failure [1]. However, whether excess extracellular volume is associated with kidney disease progression is unclear, and such studies are hampered by the lack of suitable markers of hypervolemia. In bioimpedance analysis (BIA), the ratio of extracellular water $(\mathrm{ECW})$ to total body water (TBW) has been used as an indicator of the fluid volume status [2-6]. However, the $\mathrm{ECW} / \mathrm{TBW}$ ratio may not be an ideal measurement of volume overload. The ECW/TBW ratio is affected not only by changes in the ECW, but also by changes in the intracellular water (ICW) component of TBW. The amount of ICW decreases with aging [7]. Therefore, an increased ECW/TBW ratio may be also observed in lean, elderly patients without edema. Using the Body Composition Monitor, which assesses the extracellular volume status by comparing the measured ECW to the expected ECW, Tsai et al. recently reported an association between fluid overload and adverse kidney outcomes in the short term in patients with advanced stage 4 to 5 CKD [8].

Anthropometric formulas combined with tracer dilution techniques have been extensively used to calculate TBW in patients with CKD. The Watson formula, which is routinely used to calculate the efficiency of dialysis, was originally derived from pooled data of healthy subjects and provides information about adequate fluid volume adjusted for age and sex [9]. We hypothesized that the ratio of the ECW as measured by BIA (ECW $\left.\mathrm{BIA}_{\mathrm{BA}}\right)$ to the TBW as calculated using the Watson formula $\left(\mathrm{TBW}_{\text {Watson }}\right)$ might also be used to assess the extracellular fluid status in clinical practice. In addition, we assessed the extracellular volume status using the ratio of the measured ECW to the expected ECW as calculated by an equation described by Peters et al. based on healthy potential renal transplant donors [10].

The goals of the present study were to (1) identify factors associated with the extracellular volume status, (2) investigate the relationship between the extracellular volume status and renal outcomes in patients with CKD and $\mathrm{n}$ study the prognostic performance of parameters associated with the extracellular volume status in predicting adverse renal outcomes.

\section{Methods}

\section{Study design}

This study was approved by the Ethics Committee of Toho University Omori Medical Center, Tokyo, Japan (approval number: 25-252) and was performed in adherence with the Declaration of Helsinki. Informed consent was obtained from all participants. Of 170 patients with CKD aged $\geq 20$ years with BIA body composition measurements obtained from August 2005 to January 2009, 149 patients with complete clinical data in whom we could assess anthropometric measurements, blood pressure, proteinuria, and kidney function at the same time were studied.

The following patient characteristics and parameters were examined: age, sex, height, body weight, body mass index (BMI), underlying renal disease, office blood pressure, serum albumin level, total cholesterol level, triglyceride level, fasting blood glucose level, uric acid level, serum creatinine $(\mathrm{Cr})$ level, estimated glomerular filtration rate (eGFR), urinary protein to creatinine ratio in a random urine sample (UPCR), and use of diuretics and antihypertensive agents. In total, 127 of the 147 patients were able to provide a 24-hour urine sample. Hyperuricemia was diagnosed if the uric acid level was $>7.0 \mathrm{mg} / \mathrm{dL}$ for men and $>5.7 \mathrm{mg} / \mathrm{dL}$ for women in accordance with previously performed population surveys [11]. The eGFR was calculated according to the CKD-Epidemiology Collaboration equation [12]. Resistant hypertension was defined as uncontrolled blood pressure (office systolic blood pressure of $\geq 130 \mathrm{mmHg}$ or office diastolic blood pressure of $\geq 80 \mathrm{mmHg}$ ) despite antihypertensive therapy using three or more medications, including diuretics. Controlled blood pressure using four or more drugs was also defined as resistant hypertension [13,14]. Patients were followed up until August 2013 (median, 1789 days; 10th-90th percentile, 422-2689 days) unless loss to follow-up or death occurred.

\section{Adverse outcomes}

Cox proportional hazards models with time-dependent covariates were used to compare renal outcomes and allcause mortality. The endpoint of the study was the time to the first record of either one of the following adverse events: $\geq 50 \%$ decline in the GFR relative to baseline or initiation of either dialysis therapy or renal transplantation $[15,16]$.

\section{Assessment of body fluid status}

BIA was performed in a standard manner with the patient lying supine on a flat, nonconductive bed for at least 15 min. A segmental BIA instrument (Inbody S20 Biospace Co., Ltd., Seoul, Korea [www.biospaceamerica. com]) with eight tactile electrodes was used. The microprocessor-controlled switches and BIA analyzer were activated, and segmental resistances of the arms, trunk, and legs were measured at four frequencies (5, 50,250 , and $500 \mathrm{kHz}$ ). Thus, 20 segmental resistances were measured for each patient. Using the BIA software, the sum of the segmental resistances for each body segment was used to calculate the TBW, ICW, and ECW. Each measured fluid compartment was expressed as both the actual value and percentage of the body weight. 
We calculated the expected ECW according to the Peters formula $\left(\mathrm{ECW}_{\text {Peters }}\right):(-2.47 \times 0.842+8.76 \times$ body surface area) for men and $(-1.96 \times 0.572+8.05 \times$ body surface area) for women [10]. We also estimated the TBW according to the Watson formula $\left(\mathrm{TBW}_{\text {Watson }}\right):(2.447+$ $[0.0956 \times$ age $]+[0.1074 \times$ height $]+[0.3362 \times$ body weight $])$ for men and $(-2.097+[0.1069 \times$ height $]+[0.3362 \times$ body weight]) for women [9]. The body surface area was estimated using the equation described by Haycock et al. [17]. The ratio of $\mathrm{ECW}_{\mathrm{BIA}}$ to $\mathrm{ECW}_{\text {Peters }}$ or the percentage of $\mathrm{ECW}_{\mathrm{BIA}}$ to $\mathrm{TBW} \mathrm{W}_{\text {atson }}$ were modified as indicators of excess fluid volume [7].

\section{Statistical analyses}

Data were statistically analyzed using JMP 9.0 software (SAS Institute, Inc., Cary, NC, USA). Patients were classified into tertiles according to their extracellular volume status. Because all parameters used to assess the extracellular volume status had different actual values and percentages between men and women, we divided the tertile values by men and women and combined tertiles 1,2 , and 3 in men and women, respectively. Each measured value was expressed as either mean \pm standard deviation or percentage. Statistical significance was assessed using a linear regression model to compare the mean values of possible risk factors among the tertile groups [18] and were checked by one-way analysis of variance for continuous variables and Pearson's chi-squared test for categorical variables. We constructed Bland-Altman and residual plots of $\mathrm{TBW}_{\mathrm{BIA}}$ and $\mathrm{TBW}_{\text {Watson }}$ to assess bias. Correlations between variables were examined using Pearson's product-moment correlation coefficient. Logistic and linear regression analyses were used to analyze the association between the \% $\mathrm{ECW}_{\mathrm{BIA}} / \mathrm{TBW} W_{\text {Watson }}$ ratio and demographic factors. Explanatory variables that were significantly correlated $(P<$ 0.1 ) with the $\% \mathrm{ECW}_{\mathrm{BIA}} / \mathrm{TBW}_{\mathrm{Watson}}$ ratio were then subjected to multivariate analysis to identify independent associations. Kaplan-Meier survival curves for adverse renal outcomes were generated. A Cox regression model with time-dependent covariates was used to analyze the relationship between the $\% \mathrm{ECW}_{\mathrm{BIA}} / \mathrm{TBW}_{\text {Watson }}$ ratio and adverse renal outcomes, and analyzed values were expressed as hazard ratios (HRs) with corresponding 95\% confidence intervals (CIs). Receiver operating characteristic curve analysis was used to identify the best prognostic factor for adverse renal outcomes. A probability $(P)$ value of $<0.05$ was considered to be statistically significant.

\section{Results}

Comparison between percentage of ECW in body weight, ratio of $\mathrm{ECW}_{\mathrm{BIA}}$ to $\mathrm{ECW}_{\text {Peters, }}$ and percentage of $\mathrm{ECW}_{\mathrm{BIA}}$ to $\mathrm{TBW}_{\text {Watson }}$

We compared three parameters of extracellular volume status assessment: (\% $\mathrm{ECW}_{\mathrm{BIA}}$ in body weight, $\mathrm{ECW}_{\mathrm{BIA}} /$
$\mathrm{ECW}_{\text {Peters }}$ ratio, and $\% \mathrm{ECW}_{\mathrm{BIA}} / \mathrm{TBW}_{\text {Watson }}$ ratio). As shown in Figure 1, patients with a higher $\% \mathrm{ECW}_{\mathrm{BIA}}$ were more likely to have a lower body weight. The $\% \mathrm{ECW}_{\text {BIA }}$ in body weight was negatively correlated with body weight regardless of the actual extracellular volume status. On the other hand, patients in a higher tertile with respect to the other two parameters were more likely to have both higher actual values and higher extracellular volume percentages. We also observed preliminarily correlations between these three parameters and the patients' main demographic characteristics (Additional file 1: Table S1). The $\% \mathrm{ECW}_{\text {BIA }}$ in body weight was higher among patients with lower body weights and was only correlated with the serum albumin level. The $\mathrm{ECW}_{\mathrm{BIA}} / \mathrm{ECW}_{\text {Peters }}$ ratio was positively correlated with a higher prevalence of resistant hypertension and furosemide use, lower serum albumin level, and higher UPCR level; it was also highly dependent upon height, explaining why height was included in the equation described by Peters et al. [10]. The $\% \mathrm{ECW}_{\mathrm{BIA}} /$ $\mathrm{TBW}_{\text {Watson }}$ ratio exhibited a significant correlation with most demographic factors among these three parameters. Interestingly, the $\mathrm{ECW}_{\mathrm{BIA}} / \mathrm{ECW}_{\text {Peters }}$ ratio and the \%ECW${ }_{\mathrm{BIA}} / \mathrm{TBW}_{\text {Watson }}$ ratio showed different associations with age. Age tended to increase as the $\mathrm{ECW}_{\text {BIA }} / \mathrm{ECW}_{\text {Peters }}$ ratio decreased, whereas age tended to increase as the $\% \mathrm{ECW}_{\mathrm{BIA}} /$ $\mathrm{TBW}_{\text {Watson }}$ ratio increased. This difference may be explained by the fact that $\mathrm{ECW}_{\mathrm{BIA}}$ decreased with age in our population but that $\mathrm{ECW}_{\text {Peters }}$ did not decrease with age in a potential healthy donor population [10]. For the abovementioned reasons, we used the $\% \mathrm{ECW}_{\mathrm{BIA}} / \mathrm{TBW}_{\text {Watson }}$ ratio as the main parameter of the extracellular volume status.

\section{Correlations between age and an imbalance between measured ICW and ECW}

Correlations between age and an imbalance between the measured ICW and ECW are presented in Figure 2. Both the ICW and ECW content decreased with age, although the trend was predominantly observed in the ICW content (correlation between ICW and age, $r=-0.30, P=0.001$; correlation between ECW and age, $r=-0.18, P=0.03$ ). Thus, the percentage of measured $\mathrm{ECW}_{\mathrm{BIA}}$ in $\mathrm{TBW}_{\mathrm{BIA}}$ had a moderately positive correlation with age $(r=0.60, P<$ $0.001)$.

\section{Relationship between measured $\mathrm{TBW}_{\mathrm{BIA}}$ and estimated TBW Watson by sex}

The mean differences between the measured TBW $\mathrm{BIA}_{\mathrm{A}}$ and estimated $\mathrm{TBW}_{\mathrm{Watson}}$ for men and women were $0.41 \mathrm{~L}(95 \% \mathrm{CI},-0.19$ to $1.01 ; P=0.17)$ and $-0.75 \mathrm{~L}$ (95\% CI, -1.27 to $-0.23 ; P=0.01$ ), respectively (Additional file 2: Figure S1A and C). Residual plots showed that bias in the measured TBW $\mathrm{BIA}_{\mathrm{BA}}$ and estimated $\mathrm{TBW}_{\mathrm{W}_{\text {atson }} \text { were }}$ greatest at higher measured $\mathrm{TBW}_{\mathrm{BIA}}$ values for both sexes (Additional file 2: Figure S1B and D). 


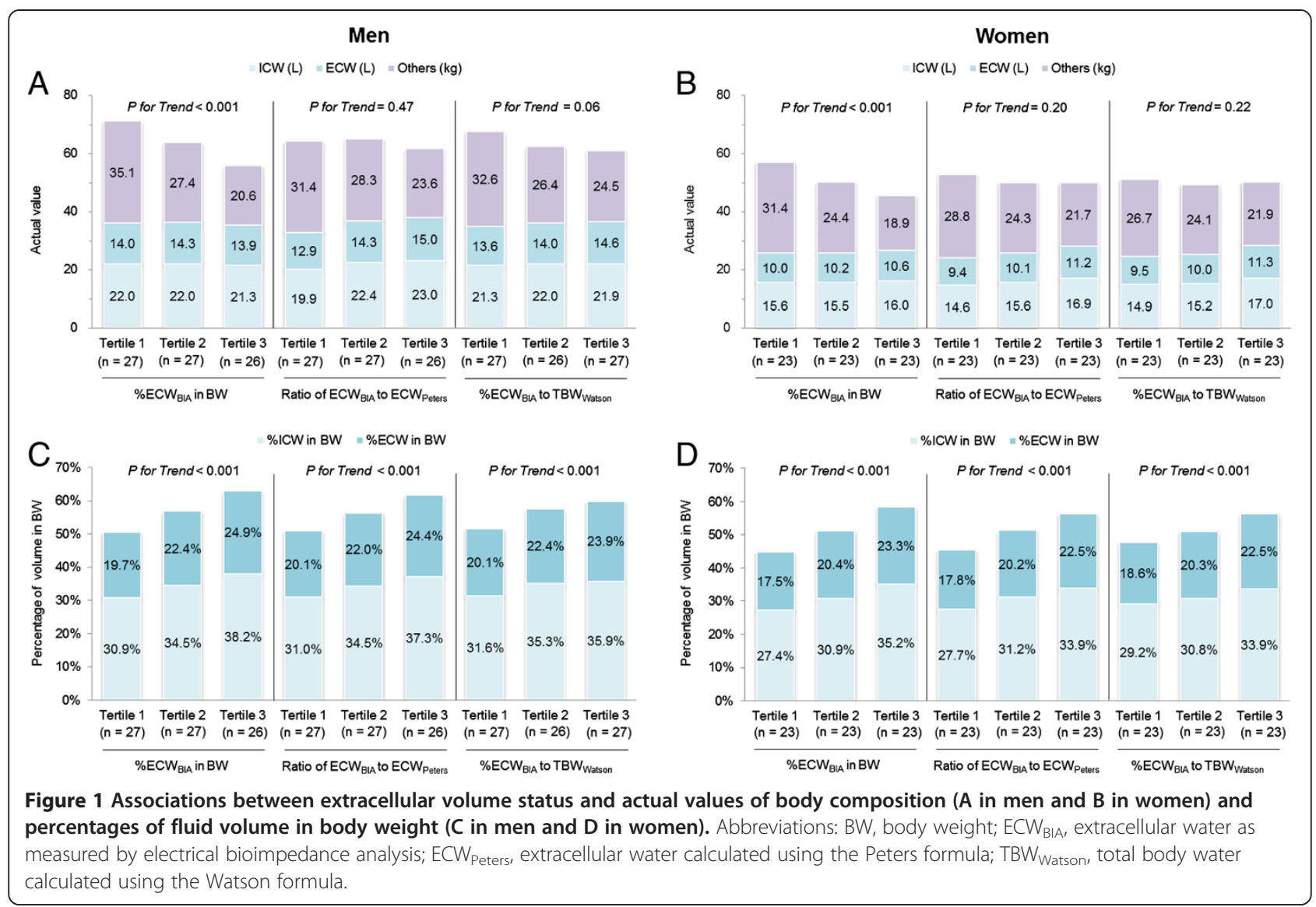

\section{Patient characteristics at the time of BIA}

The characteristics of the 149 patients according to the tertiles of the $\% \mathrm{ECW}_{\mathrm{BIA}} / \mathrm{TBW}_{\text {Watson }}$ ratio are listed in Table 1 . The tertile values were $38.3 \%$ and $41.1 \%$ in men and $37.0 \%$ and $39.4 \%$ in women. Of the 149 patients, 80 were men and 69 were women, with a mean age of 63.7 \pm 16.1 years; 24 patients $(16.1 \%)$ had diabetes mellitus. The mean eGFR was $63.8 \pm 50.1 \mathrm{ml} / \mathrm{min}$ per $1.73 \mathrm{~m}^{2}$. Patients with a higher $\% \mathrm{ECW}_{\mathrm{BIA}} / \mathrm{TBW}_{\mathrm{W}_{\text {atson }}}$ ratio tended to have diabetes mellitus, resistant hypertension, a lower diastolic blood pressure, a higher pulse pressure, a higher serum creatinine level, a lower eGFR, a lower serum albumin level, a higher UPCR level, and a higher prevalence of furosemide use $(P<0.05)$. In contrast, there were no significant differences in the 24-hour urinary sodium excretion rate among the three groups. Patients in the lowest tertile were more likely to have a higher BMI than were those in the higher tertiles $\left(24.0 \pm 4.2 \mathrm{~kg} / \mathrm{m}^{2}\right.$ in the lowest tertile vs. $22.0 \pm 3.5 \mathrm{~kg} / \mathrm{m}^{2}$ in the second tertile and $21.6 \pm 2.9 \mathrm{~kg} / \mathrm{m}^{2}$ in the highest tertile, $P=0.001$ ). Notably, patients in the higher tertiles of the $\% \mathrm{ECW}_{\mathrm{BIA}} /$ $\mathrm{TBW}_{\text {Watson }}$ ratio were more likely to have a higher percent body weight of TBW, ICW, and ECW.

\section{Independent factors associated with extracellular volume status}

Age, male sex, diabetes mellitus, the eGFR, and the UPCR level were correlated with the $\% \mathrm{ECW}_{\mathrm{BIA}} / \mathrm{TBW}_{\mathrm{Watson}}$ ratio in univariate analysis. In the multivariate analysis, male sex and UPCR remained independently associated with the $\% \mathrm{ECW}_{\mathrm{BIA}} / \mathrm{TBW}_{\text {Watson }}$ ratio (Table 2).

\section{Correlation between serum albumin and extracellular volume status}

As shown in Additional file 3: Figure S2 (online), the serum albumin level was weakly correlated with the $\% \mathrm{ECW}_{\text {BIA }}$ in body weight $(r=-0.32, P<0.001)$ and $\mathrm{ECW}_{\mathrm{BIA}} / \mathrm{ECW}_{\text {Peters }}$ ratio $(r=-0.24, P=0.004)$ and was moderately correlated with the \%ECW $\mathrm{EIA}_{\mathrm{BI}} / \mathrm{TBW}_{\text {Watson }}$ ratio $(r=-0.44, P<0.001)$.

\section{Correlations of $\% \mathrm{ECW}_{\mathrm{BIA}} / \mathrm{TBW}_{\text {Watson }}$ with renal outcome and all-cause mortality}

During the follow-up period, 52 patients had adverse renal outcomes (8.5 per 100.0 patient years) and 25 had all-cause death (4.6 per 100.0 patient years). The Kaplan-Meier analysis curves revealed significant differences in renal outcomes among the different $\% \mathrm{ECW}_{\mathrm{BIA}} /$ 


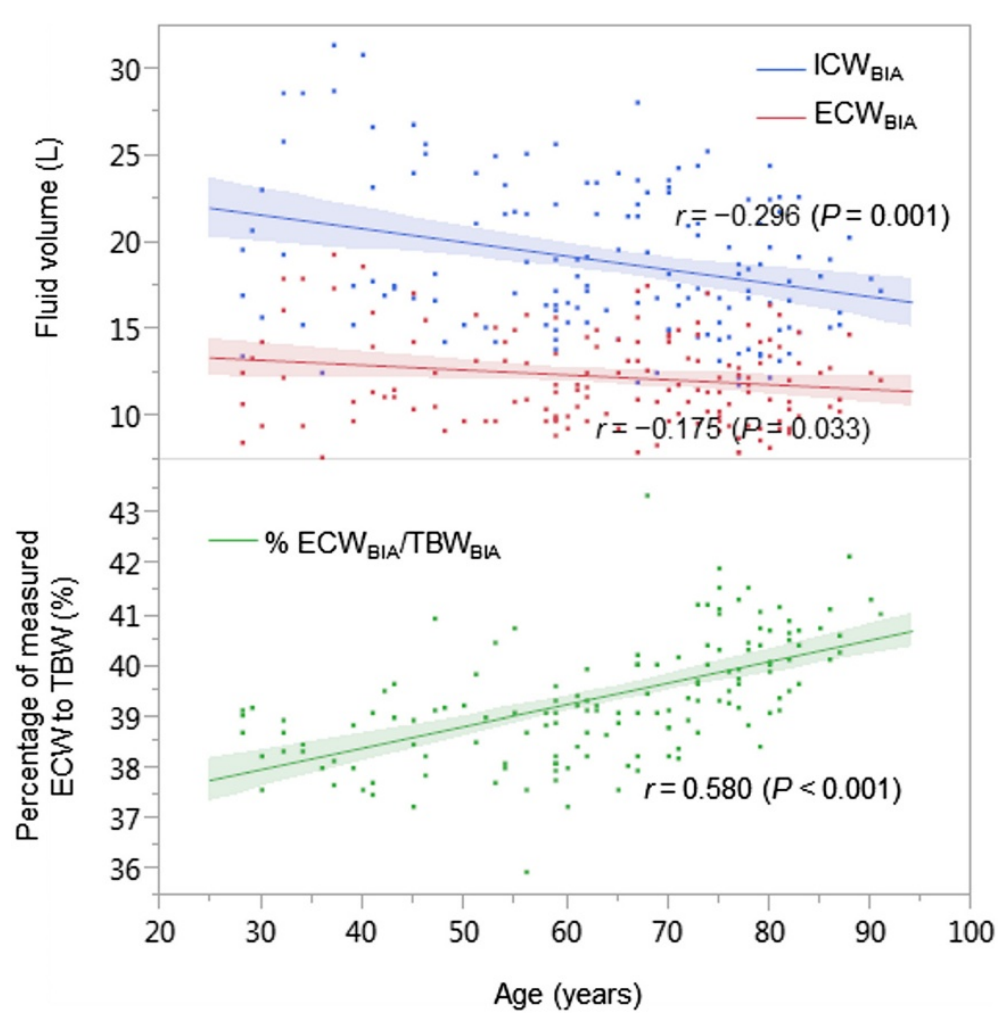

Figure 2 Correlations between age with an imbalance between ICW and ECW. Abbreviations: ICW $W_{B \mid A}$, intracellular water; ECW water; $T_{B W}$ BIA, total body water as measured by bioimpedance analysis.

TBW $W_{\text {Watson }}$ tertiles (Figure 3). Patients in the highest tertile were at greater risk of disease progression (16.6 per 100.0 patient years) than were those in the lowest (8.1 per 100.0 patient years) and second tertiles (5.6 per 100.0 patient years $)(P=0.01)$. After adjustment for covariates including age, sex, diabetes mellitus, systolic blood pressure, UPCR level, and baseline eGFR, the $\% \mathrm{ECW}_{\mathrm{BIA}} /$ $\mathrm{TBW}_{\text {Watson }}$ ratio was found to be significantly associated with adverse renal outcomes (HR, 1.21; 95\% CI, 1.10-1.34; $P<0.001$ ) (Table 3). As shown in Additional file 4: Figure S3 (online), we also depicted the Kaplan-Meier analysis curves for renal outcomes among the different tertiles of $\% \mathrm{ECW}_{\mathrm{BIA}}$ in body weight and $\mathrm{ECW}_{\mathrm{BIA}} / \mathrm{ECW}_{\text {Peters }}$ ratio. Patients in the highest $\% \mathrm{ECW}_{\mathrm{BIA}} / \mathrm{ECW}_{\text {Peters }}$ tertile exhibited significantly lower renal survival than did the other two groups. In contrast, no significant differences were noted in renal survival according to the different tertiles of $\% \mathrm{ECW}_{\mathrm{BIA}}$ in body weight or tertiles 1 or 2 of $\% \mathrm{ECW}_{\mathrm{BIA}} /$ $\mathrm{ECW}_{\text {Peters }}(P=0.10)$.

\section{Prognostic performance of $\% \mathrm{ECW}_{\mathrm{BIA}} / \mathrm{TBW}_{\text {Watson }}$ ratio in predicting adverse renal outcomes}

We constructed receiver operating characteristic curves to determine the cut-off of the $\% \mathrm{ECW}_{\mathrm{BIA}} / \mathrm{TBW} \mathrm{W}_{\text {atson }}$ ratio that best predicts adverse renal outcomes. The optimal cut-off values for all patients, male patients, and female patients were $39.9 \%, 42.2 \%$, and $40.0 \%$, respectively. Using these cut-off values, the respective areas under the curve were 0.655 (95\% CI, 0.552-0.746), 0.665 (95\% CI, 0.527-0.780), and 0.620 (95\% CI, 0.453-0.763) (Figure 4).

\section{Discussion}

This study revealed that the $\mathrm{ECW}_{\mathrm{BIA}} / \mathrm{TBW}_{\mathrm{W}_{\text {atson }}}$ ratio reflects the extracellular volume status and is associated with adverse renal outcomes in patients with CKD. Additionally, our findings showed that the $\% \mathrm{ECW}_{\mathrm{BIA}} /$ $\mathrm{TBW}_{\text {Watson }}$ ratio is influenced by sex and proteinuria. Finally, age affected the balance between the ICW and ECW and increased the percentage of ECW in the body fluid composition.

BIA methods are used to noninvasively measure the ECW, ICW, and TBW and calculate the free fat mass and fat based on empirical equations [19]. However, the measure of free fat mass is influenced by the TBW content because the fat free mass is obtained by dividing the TBW by 0.733 . The $\mathrm{ECW}_{\mathrm{BIA}} / \mathrm{TBW}_{\mathrm{BIA}}$ ratio increases along with ECW excess and decreased ICW. Therefore, the $\mathrm{ECW}_{\mathrm{BIA}} / \mathrm{TBW}_{\mathrm{BIA}}$ ratio appears to be an inadequate marker of the volume status [7]. In fact, the present findings show that the percentage of $\mathrm{ECW}_{\mathrm{BIA}}$ in $\mathrm{TBW}_{\mathrm{BIA}}$ was positively correlated with age. Two recent studies used a 
Table 1 Patients characteristics separated by tertiles of the percentage of ECW BIA $_{\text {to }}$ TBW $_{\text {Watson }}$

\begin{tabular}{|c|c|c|c|c|}
\hline \multirow[t]{2}{*}{ Population characteristics } & \multicolumn{3}{|c|}{ Percentage of $\mathrm{ECW}_{\text {BIA }}$ to $\mathrm{TBW}_{\text {Watson }}$} & \multirow{2}{*}{$\begin{array}{l}P \text { for } \\
\text { ANOVA }\end{array}$} \\
\hline & $\begin{array}{c}\text { Tertile } 1(n=50)(27 \text { men } \\
\text { with }<38.3 \% \text { and } 23 \\
\text { women with }<37.0 \%) \\
\end{array}$ & $\begin{array}{c}\text { Tertile } 2(n=49)(26 \text { men } \\
\text { with } 38.3 \%-41.0 \% \text { and } 23 \\
\text { women with } 37.0 \%-39.4 \%)\end{array}$ & $\begin{array}{c}\text { Tertile } 3(n=50)(27 \text { men } \\
\text { with } \geq 41.1 \% \text { and } 23 \\
\text { women with } \geq 39.5 \%)\end{array}$ & \\
\hline Age, years & $62.0 \pm 16.6$ & $61.8 \pm 15.1$ & $67.1 \pm 16.4$ & 0.18 \\
\hline Height, cm & $159 \pm 10$ & $159 \pm 11$ & $161 \pm 8$ & 0.46 \\
\hline Weight, kg & $61 \pm 15$ & $56 \pm 12$ & $56 \pm 10$ & 0.09 \\
\hline Body surface area, $\mathrm{m}^{2}$ & $1.62 \pm 0.21$ & $1.56 \pm 0.21$ & $1.58 \pm 0.16$ & 0.41 \\
\hline Body mass index, $\mathrm{kg} / \mathrm{m}^{2}$ & $24.0 \pm 4.2$ & $22.0 \pm 3.5$ & $21.6 \pm 2.9$ & $<0.01$ \\
\hline \multicolumn{5}{|l|}{ Underlying disease } \\
\hline Glomerulonephritis, n (\%) & $23(46.0)$ & $22(45.0)$ & $17(34.0)$ & 0.41 \\
\hline Diabetes mellitus, $n$ (\%) & $4(8.0)$ & $7(14.3)$ & $13(26.0)$ & $<0.05$ \\
\hline Nephrosclerosis, $n$ (\%) & $9(18.0)$ & $10(20.4)$ & $9(18.0)$ & 0.94 \\
\hline ADPKD, $n(\%)$ & $0(0.0)$ & $0(0.0)$ & $1(2.0)$ & 0.37 \\
\hline Others, $n(\%)$ & $14(28.0)$ & $10(20.4)$ & $10(20.0)$ & 0.56 \\
\hline Systolic blood pressure, mmHg & $127 \pm 19$ & $122 \pm 17$ & $129 \pm 21$ & 0.19 \\
\hline Diastolic blood pressure, $\mathrm{mmHg}$ & $75 \pm 11$ & $71 \pm 9$ & $69 \pm 10$ & $<0.01$ \\
\hline Pulse pressure, $\mathrm{mmHg}$ & $52 \pm 11$ & $51 \pm 13$ & $60 \pm 17$ & $<0.01$ \\
\hline Resistant high blood pressure, $n(\%)$ & $6(12.0)$ & $12(24.5)$ & $19(38.0)$ & $<0.05$ \\
\hline \multirow[t]{2}{*}{$\mathrm{TBW}_{\mathrm{BIA}}, \mathrm{L}(\%$ in BW) } & $30.1 \pm 7.5$ & $30.9 \pm 7.2$ & $32.7 \pm 5.6$ & 0.14 \\
\hline & $(49.6 \pm 5.6)$ & $(55.3 \pm 5.6)$ & $(58.7 \pm 5.1)$ & $(<0.001)$ \\
\hline \multirow[t]{2}{*}{$I C W_{B I A}, L(\%$ in $B W)$} & $18.4 \pm 4.7$ & $18.8 \pm 4.6$ & $19.7 \pm 3.4$ & 0.30 \\
\hline & $(30.2 \pm 3.5)$ & $(33.5 \pm 3.8)$ & $(35.2 \pm 3.2)$ & $(<0.001)$ \\
\hline \multirow[t]{2}{*}{$E_{B \mid A}, L(\%$ in $B W)$} & $11.7 \pm 2.8$ & $12.1 \pm 2.6$ & $13.1 \pm 2.2$ & 0.02 \\
\hline & $(19.3 \pm 2.1)$ & $(21.7 \pm 2.0)$ & $(23.4 \pm 2.1)$ & $(<0.001)$ \\
\hline Serum creatinine, mg/dL & $1.67 \pm 1.17$ & $1.76 \pm 1.27$ & $2.55 \pm 1.78$ & $<0.01$ \\
\hline eGFR ${ }_{\text {CKD-EPI, }}$ ml/min per $1.73 \mathrm{~m}^{2}$ & $71.7 \pm 48.8$ & $71.0 \pm 52.7$ & $48.9 \pm 46.2$ & $<0.05$ \\
\hline Serum albumin, g/dL & $4.1 \pm 0.4$ & $4.0 \pm 0.4$ & $3.7 \pm 0.5$ & $<0.001$ \\
\hline Total cholesterol, mg/dL & $200 \pm 34$ & $193 \pm 36$ & $191 \pm 55$ & 0.53 \\
\hline Triglycerides, mg/dL & $147 \pm 71$ & $139 \pm 95$ & $129 \pm 88$ & 0.55 \\
\hline Fasting blood glucose, mg/dL & $103 \pm 19$ & $132 \pm 45$ & $134 \pm 42$ & $<0.05$ \\
\hline UPCR, $\mathrm{g} / \mathrm{g} \cdot \mathrm{Cr}$ & $0.9 \pm 1.5$ & $0.8 \pm 1.3$ & $1.6 \pm 1.9$ & $<0.05$ \\
\hline $\begin{array}{l}\text { Uric acid, }>7.0 \mathrm{mg} / \mathrm{dL} \text { in men } \\
\text { or }>6.0 \mathrm{mg} / \mathrm{dL} \text { in women, } n(\%)\end{array}$ & $23(46.9)$ & $27(55.1)$ & $32(64.0)$ & 0.23 \\
\hline 24-hour urinary urea nitrogen excretion, g/day & $2.1 \pm 1.0$ & $2.5 \pm 1.9$ & $2.2 \pm 1.5$ & 0.40 \\
\hline 24-hour urinary creatinine excretion, g/day & $1.5 \pm 1.1$ & $1.6 \pm 1.5$ & $1.5 \pm 0.8$ & 0.81 \\
\hline 24-hour urinary sodium excretion, $\mathrm{mmol} /$ day & $143 \pm 58$ & $128 \pm 50$ & $130 \pm 54$ & 0.37 \\
\hline Furosemide, $n(\%)$ & $5(10.0)$ & $6(12.2)$ & $18(36.0)$ & $<0.01$ \\
\hline Other diuretics, $n(\%)$ & $7(14.0)$ & $7(14.3)$ & $6(12.0)$ & 0.94 \\
\hline ACE inhibitors, $n$ (\%) & $14(28.0)$ & $17(34.7)$ & $16(32.0)$ & 0.77 \\
\hline AT1-R blockers, $n$ (\%) & $30(60.0)$ & $28(57.1)$ & $25(50.0)$ & 0.58 \\
\hline Other antihypertensives & $20(40.0)$ & $25(51.0)$ & $31(62.0)$ & 0.09 \\
\hline
\end{tabular}

Abbreviations: $T B W_{B I A}$ total body water as measured by bioimpedance analysis, $I C W_{B I A}$ intracellular water as measured by bioimpedance analysis, $E C W_{B I A}$ extracellular water as measured by bioimpedance analysis, $T B W_{\text {Watson }}$ total body water calculated using the Watson formula, $e G F R_{C K D-E P l}$ estimated glomerular filtration rate using the Chronic Kidney Disease Epidemiology Collaboration equation, UPCR urinary protein-to-creatinine ratio, ACE inhibitors angiotensin-converting enzyme inhibitors, AT1-receptor blockers angiotensin II type 1 receptor blockers. 
Table 2 Independent factors associated with the percentage of $\mathrm{ECW}_{\mathrm{BIA}}$ to $\mathrm{TBW}_{\mathrm{Watson}}$

\begin{tabular}{|c|c|c|c|c|}
\hline \multirow[t]{2}{*}{ Variables } & \multicolumn{2}{|c|}{ Univariate analysis } & \multicolumn{2}{|c|}{ Multivariate analysis* } \\
\hline & B $(95 \% \mathrm{Cl})$ & $P$-value & B $(95 \% \mathrm{Cl})$ & $P$-value \\
\hline Age, per 10 years of age & $0.18(0.04-0.72)$ & 0.03 & $0.01(-0.40-0.44)$ & 0.94 \\
\hline Men & $0.21(0.17-1.27)$ & 0.01 & $0.18(0.04-1.16)$ & 0.04 \\
\hline Diabetes mellitus & $0.30(0.67-2.13)$ & $<0.001$ & $0.11(-0.31-1.31)$ & 0.23 \\
\hline eGFR ${ }_{\text {CKD-EPI, }} \mathrm{ml} / \mathrm{min}$ per $1.73 \mathrm{~m}^{2}$ & $-0.24(-5.71$ to -1.11$)$ & 0.01 & $-0.05(-0.02-0.01)$ & 0.63 \\
\hline UPCR, $\mathrm{g} / \mathrm{g} \cdot \mathrm{Cr}$ & $0.32(0.33-0.96)$ & $<0.001$ & $0.17(0.20-0.87)$ & 0.01 \\
\hline
\end{tabular}

Note: *Significant factors associated with the percentage of extracellular water volume as measured by bioimpedance analysis to total body water volume calculated by the Watson formula identified in the univariate analysis $(P<0.10)$ were subjected to multivariable analysis. When the eGFR calculated by the revised formula for Japanese patients based on the Modification of Diet in Renal Disease method was used as the dependent variable instead of eGFR $\mathrm{CKD}_{\mathrm{EP}}$, the results remained similar (data not shown). Additionally, when the serum albumin level was used as the dependent variable instead of UPCR, the independent factors were sex, diabetes mellitus, and serum albumin (data not shown).

Abbreviations: $E C W_{B I A}$ extracellular water as measured by bioimpedance analysis, $T B W_{\text {Watson }}$ total body water calculated using the Watson formula, $e G F R_{C K D-E P I}$ estimated glomerular filtration rate using the Chronic Kidney Disease Epidemiology Collaboration equation, UPCR urinary protein-to-creatinine ratio, $\beta$ standardized regression coefficient, $\mathrm{Cl}$ confidence interval.

new BIA device to assess the volume status $[8,20]$. The device quantified fluid overload using reference values derived from the pooled data of healthy subjects [21]. We preliminarily used the expected ECW as calculated by the Peters formula and the expected TBW as calculated by the Watson formula as reference values of body fluid composition. These two parameters were highly correlated with each other in our study population $(r=0.97$ for men and $r=0.98$ for women) (data not shown). Peters et al. reported that the ECW was retained in healthy potential donors of older ages [10]. On the other hand, the Watson formula includes age in men as a coefficient. The measured $\mathrm{ECW}_{\text {BIA }}$ gradually decreased with age in our study. As a result, elderly patients tended to exhibit a lower $\mathrm{ECW}_{\mathrm{BIA}} / \mathrm{ECW}_{\text {Peters }}$ ratio. The $\mathrm{ECW}_{\mathrm{BIA}} / \mathrm{ECW}_{\text {Peters ratio }}$ may be not a useful maker if the extracellular volume changes with age only in patients with CKD and not in healthy subjects. The present findings show that the ratio of the measured extracellular volume to the estimated body fluid volume can serve as a useful marker of the

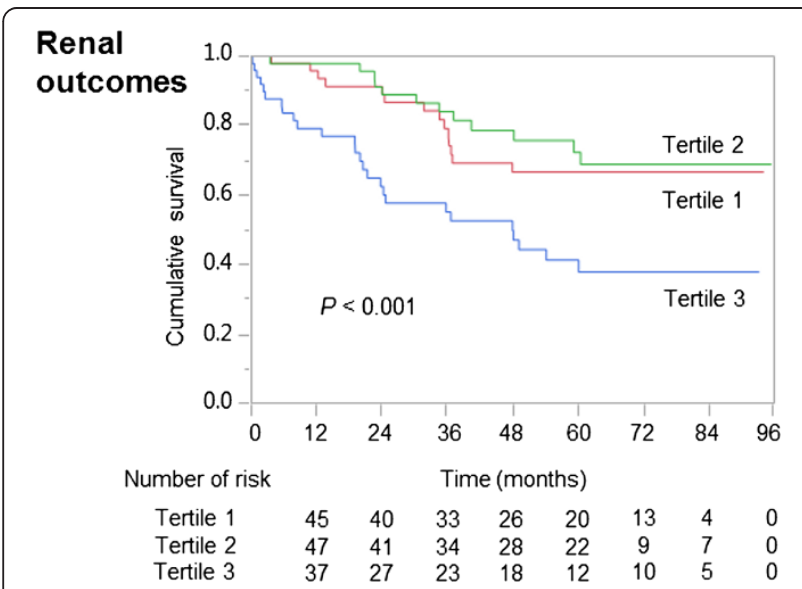

Figure 3 Kaplan-Meier survival curves for adverse renal outcomes by tertiles of $\% \mathrm{ECW}_{\mathrm{BIA}} / \mathrm{TBW}_{\text {Watson. }}$ volume status in patients with CKD. This result may be one reason that the $\% \mathrm{ECW}_{\mathrm{BIA}} / \mathrm{TBW}_{\mathrm{W}_{\text {atson }} \text { ratio exhibited }}$ a relative increase in the extracellular volume with respect to the expected fluid status, resulting in a good balance between the ICW and ECW for age. Notably, a higher extracellular volume was associated with adverse renal outcomes during a relatively long follow-up period (median duration of 4.9 years) for both of the $\mathrm{ECW}_{\mathrm{BIA}} /$ $\mathrm{ECW}_{\text {Peters }}$ ratio and the $\% \mathrm{ECW}_{\mathrm{BIA}} / \mathrm{TBW}_{\mathrm{W}_{\text {atson }}}$ ratio. Additionally, the $\mathrm{ECW}_{\mathrm{BIA}} / \mathrm{TBW}_{\text {Watson }}$ ratio was associated with traditional risk factors for kidney disease progression, including age, male sex, diabetes mellitus, higher pulse pressure, resistant hypertension, lower eGFR, lower serum albumin level, and higher proteinuria level. These findings may suggest that a higher extracellular volume causes hemodynamic instability. In contrast, sodium excretion was not associated with fluid excess. Whether sodium intake and sodium retention have a one-to-one relationship and whether sodium intake is linearly associated with the development of endstage renal disease remain unclear [22-24]. Younger subjects and those without uremia consume a higher variety of foods with various levels of sodium, protein, and total calories than do elderly people and patients with uremia. These biases may have hampered studies in this area.

Proteinuria was a strong factor in the development of a higher extracellular volume. Hypoalbuminemia, mostly in association with massive proteinuria, produces an increased interstitial fluid volume and a contracted intravascular volume contraction by a diminished oncotic pressure gradient, thus inducing renal sodium retention by activation of the renin-angiotensin-aldosterone system [25]. In addition, differences in all parameters of the extracellular volume status were found between men and women; specifically, it the extracellular volume was lower in women. The ECW and ICW contents are generally lower in women than in men because women have 
Table 3 Hazard ratios of different clinical variables for adverse renal outcomes

\begin{tabular}{|c|c|c|c|c|}
\hline \multirow[t]{2}{*}{ Variables } & \multicolumn{2}{|c|}{ Univariate analysis } & \multicolumn{2}{|c|}{ Multivariate analysis* } \\
\hline & HR $(95 \% \mathrm{Cl})$ & $P$-value & $\mathrm{HR}(95 \% \mathrm{Cl})$ & $P$-value \\
\hline Age, per 10 years of age & $1.03(1.01-1.05)$ & 0.01 & $0.84(0.69-1.04)$ & 0.10 \\
\hline Men & $1.82(1.04-3.29)$ & 0.04 & $1.13(0.60-2.10)$ & 0.70 \\
\hline Diabetes mellitus & $3.60(1.90-6.50)$ & $<0.001$ & $1.49(0.72-2.98)$ & 0.28 \\
\hline$\% \mathrm{ECW}_{\mathrm{BIA}} / \mathrm{TBW} W_{\text {Watson }}$ & $1.24(1.13-1.35)$ & $<0.001$ & $1.21(1.10-1.34)$ & $<0.001$ \\
\hline Systolic blood pressure, mmHg & $1.02(1.01-1.04)$ & $<0.001$ & $1.00(0.99-1.02)$ & 0.63 \\
\hline Baseline eGFR $R_{\text {CKD-EPI, }} \mathrm{ml} / \mathrm{min} / 1.73 \mathrm{~m}^{2}$ & $0.92(0.90-0.94)$ & $<0.001$ & $0.96(0.95-0.98)$ & $<0.001$ \\
\hline UPCR, $\mathrm{g} / \mathrm{gCr}$ & $1.29(1.15-1.42)$ & $<0.001$ & $1.20(1.01-1.38)$ & 0.04 \\
\hline
\end{tabular}

Note: *Adjusted for age, male sex, diabetes mellitus, systolic blood pressure, $\mathrm{ECW}_{\mathrm{BIA}} / \mathrm{TBW}_{\mathrm{Watson}}$ percentage, baseline estimated glomerular filtration rate, and urinary protein-creatinine ratio (variables associated with adverse renal outcomes identified in the univariate analysis $[P<0.10]$ were entered into the multivariable model). When the $\mathrm{ECW}_{\mathrm{BIA}} / \mathrm{ECW}_{\text {Peters }}$ ratio was used as the dependent variable instead of the $\% \mathrm{ECW}_{\mathrm{BIA}} / \mathrm{TBW}_{\text {Watson }}$ ratio, the results remained similar (data not shown). Abbreviations: $H R$ hazard ratio, $C l$ confidence interval, \%ECW ${ }_{B I A} / T B W_{\text {Watson }}$ percentage of extracellular water as measured by bioimpedance analysis to total body water calculated using the Watson formula, eGFR $U P C R$ urinary protein-to-creatinine ratio.

a relatively higher proportion of fat. Otherwise, differences between these two parameters may be caused by inaccuracies in the determination of the measured fluid content and estimated fluid content. Our findings revealed a difference between the measured $\mathrm{TBW}_{\mathrm{BIA}}$ and estimated $\mathrm{TBW}_{\text {Watson }}$ in both men and women (Additional file 2: Figure S1). In both sexes, these differences increased with increases in the measured $\mathrm{TBW}_{\mathrm{BIA}}$ (Additional file 2:
Figure S1B and D). Thus, differences between the actual values and reference values may contribute to the fluid volume status. The Watson formula was designed to estimate the TBW of healthy Caucasian subjects; however, it must be interpreted with caution because it may overestimate the $\mathrm{TBW}_{\text {Watson }}$ in Japanese patients, especially women. A previous study reported differences in the TBW among individuals of different races [26].
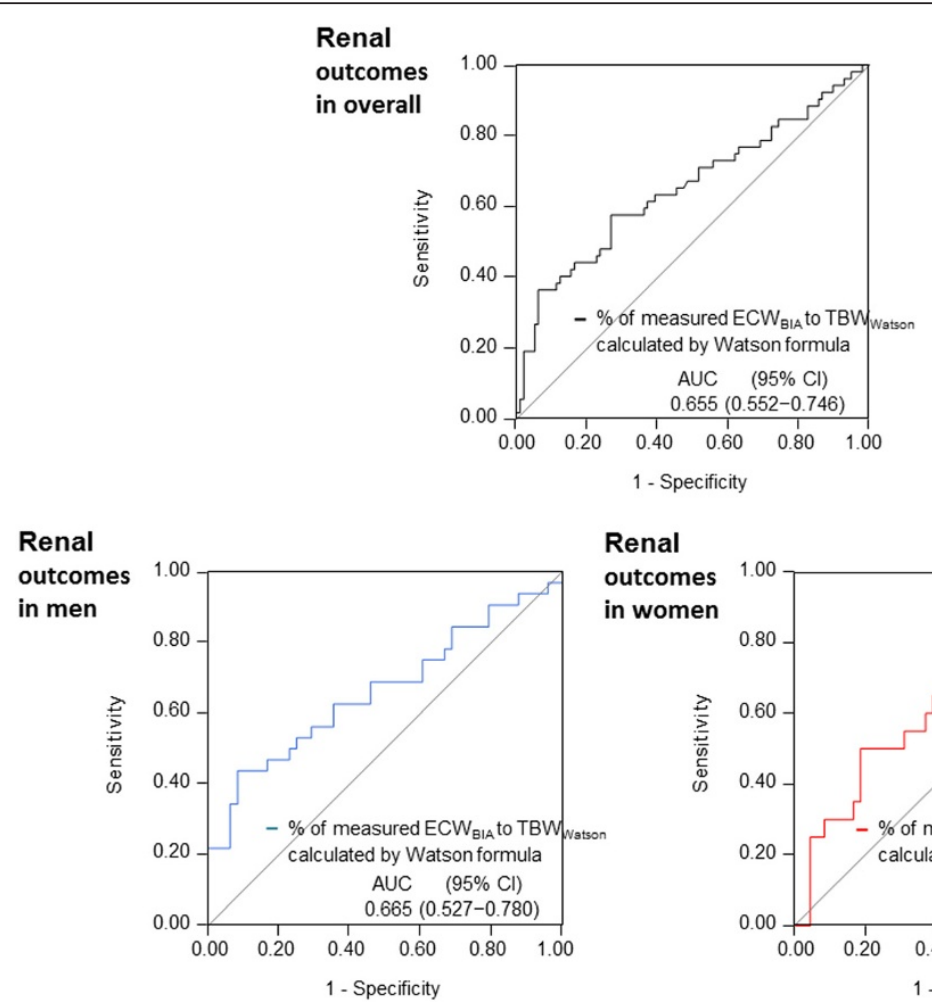

Renal

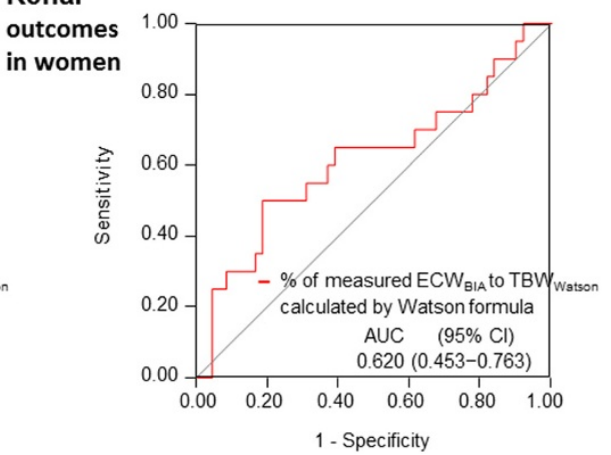

Figure 4 Receiver operating characteristic curves in the assessment of $\% \mathrm{ECW}_{\mathrm{BIA}} / \mathrm{TBW}_{\text {Watson }}$ as a prognostic factor of adverse renal outcomes in all patients, male patients, and female patients. Abbreviations: TBW BIA, total body water as measured by bioimpedance analysis; TBW Watson, total body water calculated using the Watson formula; AUC, area under the curve; $\mathrm{Cl}$, confidence interval. 
Aging cells are known to shrink and undergo apoptosis [27-29]. Fluid imbalance in patients with CKD is characterized by excess ECW associated with sodium retention [30,31] and decreased ICW associated with malnutrition [32]. In fact, patients with CKD with a leaner body mass have a higher prevalence of hypertension, poorer control of hypertension, and greater incidence of left ventricular hypertrophy. This phenomenon is known as the "obesity paradox" [33,34]. Our findings highlight the notion that elderly patients with CKD may be more susceptible to volume overload because the reduced intracellular volume caused by aging and malnutrition lessens the capacity of cells to retain fluid. This strongly supports the hypothesis that a lower serum albumin level is significantly correlated with the fluid volume.

The best \% $\mathrm{ECW}_{\mathrm{BIA}} / \mathrm{TBW}_{\text {Watson }}$ ratio cut-offs for adverse renal outcomes among male, female, and all patients were $42.2 \%, 40.0 \%$, and $39.9 \%$, respectively. These values were close to the ECW/ICW ratio of 2:3. The abovementioned threshold values may be useful for determining extracellular volume excess. However, whether removal of excess fluid improves renal outcomes remains unclear.

This study has several limitations. First, it was a retrospective cohort study conducted at a single center. However, it provided detailed information on patients' body fluid composition and had a relatively long follow-up period. Second, the $\mathrm{ECW}_{\mathrm{BIA}} / \mathrm{TBW} W_{\text {Watson }}$ ratio may not be a precise indicator of volume status; the estimated $\mathrm{TBW}_{\mathrm{W}_{\text {atson }}}$ and actual $\mathrm{TBW}_{\mathrm{BIA}}$ differ in Japanese patients. We recognize that this parameter was not compared with an indicator for congestive heart failure, such as the Nterminal of the prohormone brain natriuretic peptide. Regardless, the $\mathrm{ECW}_{\mathrm{BIA}} / \mathrm{TBW}_{\mathrm{W}_{\text {atson }}}$ ratio is associated with many factors associated with fluid volume overload; BIA can be used to easily and noninvasively assess the body fluid composition, and the results correlate with those of isotopic dilution and dual-energy X-ray absorptiometry

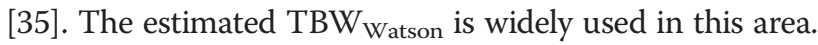
We believe that the $\mathrm{ECW}_{\mathrm{BIA}} / \mathrm{TBW}_{\mathrm{W}_{\text {atson }}}$ ratio is a practical parameter of the extracellular volume status and that the reported data will support future studies in this area.

\section{Conclusions}

In the present study, the $\mathrm{ECW}_{\mathrm{BIA}} / \mathrm{TBW}_{\text {Watson }}$ ratio was associated with adverse renal outcomes during a relatively long follow-up period. This finding suggests that a higher extracellular volume has an adverse effect on kidney disease. Proteinuria is independently associated with the extracellular volume status. Aging leads to change in the balance between the ICW content and ECW content and increases the percentage of the ECW content in the body fluid composition. Consequently, elderly patients with CKD may be susceptible to volume overload.

\section{Additional files}

\author{
Additional file 1: Table S1. Correlations between demographic \\ characteristics and parameters of extracellular volume status.
}

Additional file 2: Figure S1. Agreement between total body water as measured by bioimpedance analysis and total body water calculated using the Watson formula. Abbreviations: TBW $_{\mathrm{BI} \text {, }}$ total body water as measured by bioimpedance analysis; TBW Watson, $_{\text {, total body water }}$ calculated using the Watson formula; $\mathrm{Cl}$, confidence interval.

Additional file 3: Figure S2. Correlations between serum albumin level and \%ECW $\mathrm{BIA}_{\mathrm{A}}$ in body weight and \%ECW $\mathrm{BIA} / \mathrm{TBW}$ watson. Abbreviations: ECW $_{\text {BIA, }}$ extracellular water; TBW Watson, total body water calculated using the Watson formula.

Additional file 4: Figure S3. Kaplan-Meier survival curves for adverse renal outcomes by $(A)$ tertiles of \%ECW $\mathrm{BIA}_{\mathrm{A}}$ in body weight and (B) ratio of

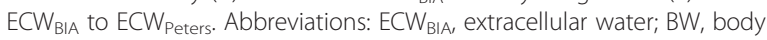
weight; TBW ${ }_{B I A}$, total body water as measured by bioimpedance analysis; TBW Watson, total body water calculated using the Watson formula.

\section{Abbreviations}

CKD: Chronic kidney disease; ECW: Extracellular water; TBW: Total body water; ICW: Intracellular water; BIA: Bioimpedance analysis; BMI: Body mass index; Cr: Serum creatinine; eGFR: Estimated glomerular filtration rate; UPCR: Urinary protein-to-creatinine ratio; HR: Hazard ratio; Cl: Confidence interval.

\section{Competing interests}

The authors declare that they have no competing interests.

\section{Authors' contributions}

$R T, Y O$, and SM conceived of the study. SM and YO contributed to the sample acquisition. RT and $Y O$ analyzed and interpreted the data. AA and KS provided scientific advice in their field of expertise. Each author contributed important intellectual content during manuscript drafting or revision and accepts accountability for the overall work by ensuring that questions pertaining to the accuracy or integrity of any portion of the work are appropriately investigated and resolved. All authors read and approved the final manuscript.

\section{Acknowledgements}

We thank Mr. Honma and Ms. Ogura, registered dieticians, for performing individualized nutritional counseling using body composition data. The authors have no financial interests.

\section{Author details}

${ }^{1}$ Department of Nephrology, School of Medicine, Faculty of Medicine, Toho University, 6-11-1 Omori-Nishi, Ota-ku, Tokyo 143-8541, Japan. Division of Nephrology, Ichiyokai Harada Hospital, Hiroshima, Japan.

Received: 19 May 2014 Accepted: 25 November 2014 Published: 1 December 2014

\section{References}

1. Stegmayr BG: Ultrafiltration and dry weight-what are the cardiovascular effects? Artif Organs 2003, 27(3):227-229.

2. Fan S, Sayed RH, Davenport A: Extracellular volume expansion in peritoneal dialysis patients. Int J Artif Organs 2012, 35(5):338-345.

3. Guo Q, Yi C, Li J, Wu X, Yang X, Yu X: Prevalence and risk factors of fluid overload in Southern Chinese continuous ambulatory peritoneal dialysis patients. PLoS One 2013, 8(1):e53294.

4. Hung SC, Lin YP, Huang HL, Pu HF, Tarng DC: Aldosterone and mortality in hemodialysis patients: role of volume overload. PLoS One 2013, 8(2):e57511.

5. Kumar S, Khosravi M, Massart A, Davenport A: Is there a role for N-terminal probrain-type natriuretic peptide in determining volume status in haemodialysis patients? Nephron Clin Pract 2012, 122(1-2):33-37.

6. Susantitaphong P, Laowaloet S, Tiranathanagul K, Chulakadabba A, Katavetin P, Praditpornsilpa K, Tungsanga K, Eiam-Ong S: Reliability of blood pressure parameters for dry weight estimation in hemodialysis patients. Ther Apher Dial 2013, 17(1):9-15. 
7. Ohashi Y, Otani T, Tai R, Tanaka Y, Sakai K, Aikawa A: Assessment of body composition using dry mass index and ratio of total body water to estimated volume based on bioelectrical impedance analysis in chronic kidney disease patients. J Ren Nutr 2013, 23(1):28-36.

8. Tsai YC, Tsai JC, Chen SC, Chiu YW, Hwang SJ, Hung CC, Chen TH, Kuo MC, Chen HC: Association of fluid overload with kidney disease progression in advanced CKD: a prospective cohort study. Am J Kidney Dis 2014, 63(1):68-75.

9. Watson PE, Watson ID, Batt RD: Total body water volumes for adult males and females estimated from simple anthropometric measurements. Am J Clin Nutr 1980, 33(1):27-39.

10. Peters AM, Perry L, Hooker CA, Howard B, Neilly MD, Seshadri N, Sobnack R, Irwin A, Snelling H, Gruning T, Patel NH, Lawson RS, Shabo G, Williams N, Dave S, Barnfield MC: Extracellular fluid volume and glomerular filtration rate in 1878 healthy potential renal transplant donors: effects of age, gender, obesity and scaling. Nephrol Dial Transplant 2012, 27(4):1429-1437.

11. Zhu Y, Pandya BJ, Choi HK: Prevalence of gout and hyperuricemia in the US general population: the National Health and Nutrition Examination Survey 2007-2008. Arthritis Rheum 2011, 63(10):3136-3141.

12. Levey AS, Stevens LA, Schmid CH, Zhang YL, Castro AF 3rd, Feldman HI, Kusek JW, Eggers P, Van Lente F, Greene T, Coresh J, CKD-EPI (Chronic Kidney Disease Epidemiology Collaboration): A new equation to estimate glomerular filtration rate. Ann Intern Med 2009, 150(9):604-612.

13. Calhoun DA, Jones D, Textor S, Goff DC, Murphy TP, Toto RD, White A, Cushman WC, White W, Sica D, Ferdinand K, Giles TD, Falkner B, Carey RM, American Heart Association Professional Education Committee: Resistant hypertension: diagnosis, evaluation, and treatment. A scientific statement from the American Heart Association Professional Education Committee of the Council for High Blood Pressure Research. Hypertension 2008, 51(6):1403-1419.

14. Chobanian AV, Bakris GL, Black HR, Cushman WC, Green LA, Izzo JL Jr, Jones DW, Materson BJ, Oparil S, Wright JT Jr, Roccella EJ, The National High Blood Pressure Education Program Coordinating Committee: The seventh report of the Joint National Committee on Prevention, Detection, Evaluation, and Treatment of High Blood Pressure: the JNC 7 report. JAMA 2003, 289(19):2560-2571.

15. Amraoui F, Bos $S$, Vogt $L$, van den Born BJ: Long-term renal outcome in patients with malignant hypertension: a retrospective cohort study. BMC Nephrol 2012, 13:71.

16. Parsa A, Kao WH, Xie D, Astor BC, Li M, Hsu CY, Feldman HI, Parekh RS, Kusek JW, Greene TH, Fink JC, Anderson AH, Choi MJ, Wright JT Jr, Lash JP, Freedman BI, Ojo A, Winkler CA, Raj DS, Kopp JB, He J, Jensvold NG, Tao K, Lipkowitz MS, Appel L, AASK Study Investigators; CRIC Study Investigators: APOL1 risk variants, race, and progression of chronic kidney disease. N Engl J Med 2013, 369(23):2183-2196.

17. Haycock GB, Schwartz GJ, Wisotsky DH: Geometric method for measuring body surface area: a height-weight formula validated in infants, children, and adults. J Pediatr 1978, 93(1):62-66.

18. Tsuruya K, Yoshida H, Nagata M, Kitazono T, Hirakata H, Iseki K, Moriyama T, Yamagata K, Yoshida H, Fujimoto S, Asahi K, Kurahashi I, Ohashi Y, Watanabe T: Association of the triglycerides to high-density lipoprotein cholesterol ratio with the risk of chronic kidney disease: analysis in a large Japanese population. Atherosclerosis 2014, 233(1):260-267.

19. Furstenberg A, Davenport A: Comparison of multifrequency bioelectrical impedance analysis and dual-energy X-ray absorptiometry assessments in outpatient hemodialysis patients. Am J Kidney Dis 2011, 57(1):123-129.

20. Hung SC, Kuo KL, Peng CH, Wu CH, Lien YC, Wang YC, Tarng DC: Volume overload correlates with cardiovascular risk factors in patients with chronic kidney disease. Kidney Int 2013, in press.

21. Chamney PW, Wabel P, Moissl UM, Muller MJ, Bosy-Westphal A, Korth O, Fuller NJ: A whole-body model to distinguish excess fluid from the hydration of major body tissues. Am J Clin Nutr 2007, 85(1):80-89.

22. Ekinci El, Clarke S, Thomas MC, Moran JL, Cheong K, Maclsaac RJ, Jerums G: Dietary salt intake and mortality in patients with type 2 diabetes. Diabetes Care 2011, 34(3):703-709.

23. Norris KC, Greene T, Kopple J, Lea J, Lewis J, Lipkowitz M, Miller P, Richardson A, Rostand S, Wang X, Appel LJ: Baseline predictors of renal disease progression in the African American Study of Hypertension and Kidney Disease. J Am Soc Nephrol 2006, 17(10):2928-2936.

24. Thomas MC, Moran J, Forsblom C, Harjutsalo V, Thorn L, Ahola A, Waden J, Tolonen N, Saraheimo M, Gordin D, Groop PH, FinnDiane Study Group: The association between dietary sodium intake, ESRD, and all-cause mortality in patients with type 1 diabetes. Diabetes Care 2011, 34(4):861-866.

25. Humphreys $\mathrm{MH}$ : Mechanisms and management of nephrotic edema. Kidney Int 1994, 45(1):266-281.

26. Davenport A, Hussain Sayed R, Fan S: The effect of racial origin on total body water volume in peritoneal dialysis patients. Clin J Am Soc Nephrol 2011, 6(10):2492-2498.

27. Bortner CD, Cidlowski JA: Cell shrinkage and monovalent cation fluxes: role in apoptosis. Arch Biochem Biophys 2007, 462(2):176-188.

28. Lang F, Gulbins E, Szabo I, Lepple-Wienhues A, Huber SM, Duranton C, Lang KS, Lang PA, Wieder T: Cell volume and the regulation of apoptotic cell death. J Mol Recognit 2004, 17(5):473-480.

29. Lang F, Ritter M, Gamper N, Huber S, Fillon S, Tanneur V, Lepple-Wienhues A, Szabo I, Gulbins E: Cell volume in the regulation of cell proliferation and apoptotic cell death. Cell Physiol Biochem 2000, 10(5-6):417-428.

30. Alvarez-Lara MA, Martin-Malo A, Espinosa M, Rodriguez-Benot A, Aljama P: Blood pressure and body water distribution in chronic renal failure patients. Nephrol Dial Transplant 2001, 16(Suppl 1):94-97.

31. Ledingham JM: Sodium retention and volume expansion as mechanisms. Am J Hypertens 1991, 4(10 Pt 2):534S-540S

32. Campbell KL, Ash S, Bauer JD, Davies PS: Evaluation of nutrition assessment tools compared with body cell mass for the assessment of malnutrition in chronic kidney disease. J Ren Nutr 2007, 17(3):189-195.

33. Agarwal R, Bills JE, Light RP: Diagnosing obesity by body mass index in chronic kidney disease: an explanation for the "obesity paradox?" Hypertension 2010, 56(5):893-900.

34. Agarwal R: Body mass index-mortality paradox in hemodialysis: can it be explained by blood pressure? Hypertension 2011, 58(6):1014-1020.

35. Cha K, Brown EF, Wilmore DW: A new bioelectrical impedance method for measurement of the erythrocyte sedimentation rate. Physiol Meas 1994, 15(4):499-508

doi:10.1186/1471-2369-15-189

Cite this article as: Tai et al:: Association between ratio of measured extracellular volume to expected body fluid volume and renal outcomes in patients with chronic kidney disease: a retrospective single-center cohort study. BMC Nephrology 2014 15:189.

\section{Submit your next manuscript to BioMed Central and take full advantage of:}

- Convenient online submission

- Thorough peer review

- No space constraints or color figure charges

- Immediate publication on acceptance

- Inclusion in PubMed, CAS, Scopus and Google Scholar

- Research which is freely available for redistribution

Submit your manuscript at www.biomedcentral.com/submit
C) Biomed Central 